\section{Unilateral Blaschkoid lichen planus in successive pregnancies}

\author{
Shiva Kumar, Rajendra Okade, \\ Yasmin Abdul Rahman
}

Department of Dermatology, Venereology and Leprosy, Sri DevarajUrs, Medical College, Tamaka, Kolar, India

\begin{abstract}
A number of genetic, congenital and acquired dermatoses have been known to follow Blaschko's lines. A common disorder like lichen planus can very rarely present with pruritic lesions in atypical patterns such as unilateral distribution, painful eruptions and along Blaschko's lines. Various triggering factors varying from viral infections and vaccinations to trauma have been implicated in lichen planus. We describe a female patient in the second trimester of her second pregnancy who developed unilateral lichen planus along Blaschko's lines during both pregnancies. No case of lichen planus along Blaschko's lines recurring during pregnancy is reported so far. Could pregnancy itself be a contributory factor towards onset of lichen planus in this case?
\end{abstract}

\section{Introduction}

Lichen planus (LP) is a common inflammatory disorder that affects skin, mucous membrane, nails and hair. It is classically characterised by pruritic, shiny, violaceous, flat topped, polygonal papules which retain skin lines and maybe closely aggregated or widely dispersed. ${ }^{1}$ Various etiological factors include immunological mediation, chronic liver disease, hepatitis $\mathrm{C}$ infection ${ }^{2-3}$ and hereditary causes among others . Variants of this disorder include hypertrophic LP, follicular LP, linear LP, annular LP, vesicobullous LP, actinic LP, erosive and nonerosive mucous membrane LP. ${ }^{1}$

Blaschko's lines were delineated in 1901 by a German dermatologist Alfred Blaschko . The original description by Blaschko referred to a system of lines on the human skin which the linear naevi and dermatoses follow. ${ }^{4}$ The pattern is attributed to lines of migration of epidermal cells during embrogenesis. ${ }^{5}$ These lines are curved over scalp and face, V shaped in upper spine, inverted $U$ shaped over chest and upper arm, S - shaped whorls on the chest and abdomen and perpendicular over the front and back of extremities. Types of Blaschko's pattern include narrow band, large band, checkerboard and phylloid. ${ }^{6}$

\section{Case Report}

A 24-year-old female in the $2^{\text {nd }}$ trimester of her $2^{\text {nd }}$ pregnancy presented with a history of itchy skin lesions which started over dorsum of her left hand 3 months back. New lesions progressively appeared in a linear pattern extending proximally to involve the left forearm, arm and shoulder. Simultaneously new elevated discoloured lesions appeared over left flank, abdomen and breast.

Patient had similar lesions in the same areas during her $1^{\text {st }}$ pregnancy 2 year's back which had spontaneously resolved within 3 months after delivery with residual post inflammatory hyperpigmentation in the affected areas which still persisted.

On examination, violaceus flat topped 2-5 mm papules were noted, some of which showed typical lacy white pattern of Wickham's striae extending from left thumb uptoleft arm in a wave like pattern along Blaschko's lines (Figure 1), they were discrete at few places while at others they appeared to be coalescing. Similar papules in a wavy pattern were noted over left shoulder, upper back (Figure 2), discontinuous papules and hyperpigmented macules were seen over left flank, abdomen (Figure 3) and left breast in 3 curved lines. Post inflammatory hyperpigmented macules of lesions which developed during the previous pregnancy were seen along the same Blaschko's lines. None of the eruptions crossed the midline. The patient had no oral lesions or nail changes. A working diagnosis of lichen planus was made. Preliminary routine investigations were within normal limits and tests for Hepatitis B and C were negative. Punch biopsy of left forearm lesions showed typical features of lichen planus (Figure 4).

\section{Discussion}

Lichen planus is a subacute to chronic dermatosis, which is benign and self limiting , although recurrences can occur. The disease has a predilection for flexor surfaces of forearms, legs and glans penis. Inverse lichen planus eruption occurs in flexures like axilla, inframammary folds and groins. Eruptions may be localised or extensive and Koebner's phenomenon is commonly seen. Oral lesions of lichen planus are frequently seen either as sole manifestations or associated with cutaneous involvement. Apart from the known variants of lichen planus, a few rare cases of
Correspondence: Shiva Kumar, No. 66, 11th cross, Indiranagar, 1st stage, Bangalore- 560038 , India.

Tel. +91-9886151969.

E-mail: dermashiva@rediffmail.com

Key words: lichen planus, pregnancy, Blaschko'slines.

Received for publication: 23 August 2011. Accepted for publication: 6 September 2011.

This work is licensed under a Creative Commons Attribution NonCommercial 3.0 License (CC BYNC 3.0).

(C) Copyright S. Kumar et al., 2011

Licensee PAGEPress, Italy

Dermatology Reports 2011; 3:e35

doi:10.4081/dr.2011.e35

lichen planus along Blaschko's lines has been described. ${ }^{1}$

Histopathology examination reveals compact orthokeratosis, wedge shaped hypergranulosis irregular acanthosis, vacuolar alteration of the basal layer. Rete ridges may show saw - tooth appearance. Degenerating epidermal cells form colloid bodies and a band like infiltration of lymphocytes may obliterate the dermo - epidermal junction. ${ }^{7}$

Blaschko's lines do not correspond to any vascular, lymphatic or neural structures and are invisible and become apparent in certain disease states such as pigmentary disorders (naevus achromicus, epidermal naevus), $\mathrm{X}$ linked genetic skin disease (Incontinentia pigmenti), acquired inflammatory skin disorders (LP, lichen striatus) and chimerism. ${ }^{6}$

Case reports of unilateral cutaneous lichen planus, ${ }^{1,8-9}$ lichen planus along with unilateral mucosal involvement, ${ }^{10}$ linear lichen pigmentosus $^{11}$ and painful atrophic lichen planus ${ }^{12}$ have been reported along Blaschko's lines. Long et al. described a case of bilateral linear lichen planus along Blaschko's lines. ${ }^{13}$ Wolfs isotopic response is the occurrence of new skin disorder exactly at the site of another, unrelated and already resolved skin disease, this phenomenon has been seen in dermatomal lichen planus following herpes zoster at the same location. ${ }^{14}$ Krasowska et al. reported a case of a 33 year old healthy woman who developed recurrent unilateral lichen planus along Blaschko's lines following 3 successive deliveries of healthy babies ${ }^{15}$.

Our patient presented with history of onset of lesions during first trimester and to the best of our knowledge this is the first case of lichen planus along Blaschko's lines occurring during successive pregnancies. Considering the fact that various known and idiopathic causes have been known to trigger 
lichen planus, a need to follow up the patient in current and subsequent pregnancies becomes essential to find a positive correlation between pregnancy and lichen planus and to establish whether pregnancy itself could have triggered lichen planus.

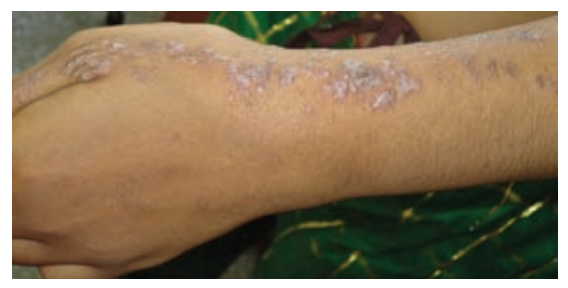

Figure 1. Typical violaceous papules over thumb and forearm in a linear distribution.

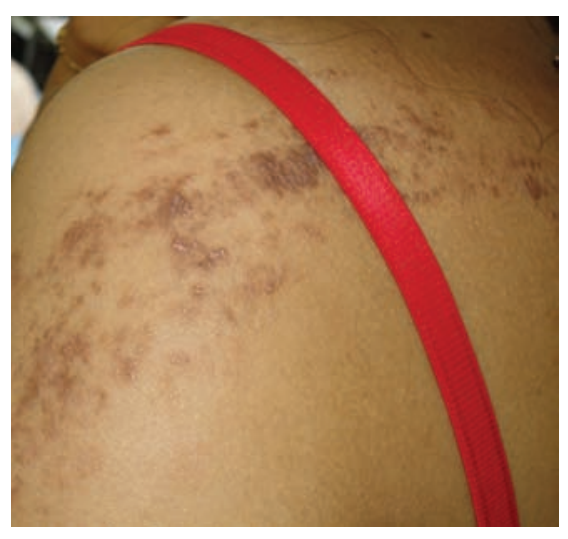

Figure 2. Pigmented papules and macules over shoulder.

\section{References}

1. Lehman JS, Tollefson MM, Gibson LE. Lichen planus. Int J Dermatol 2009;48:68294.

2. Bellman B, Reddy RK, Falanga V. Lichen

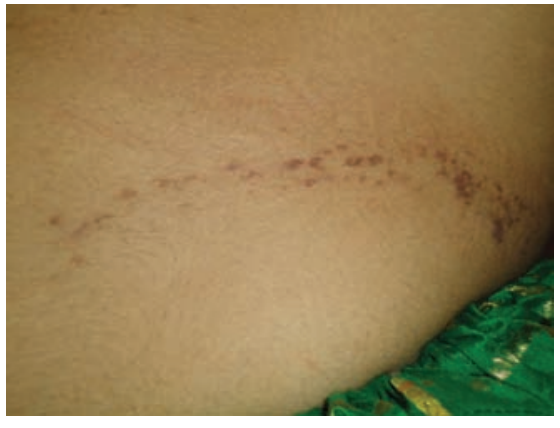

Figure 3. Gravid abdomen showing linear pigmented macules and papules.

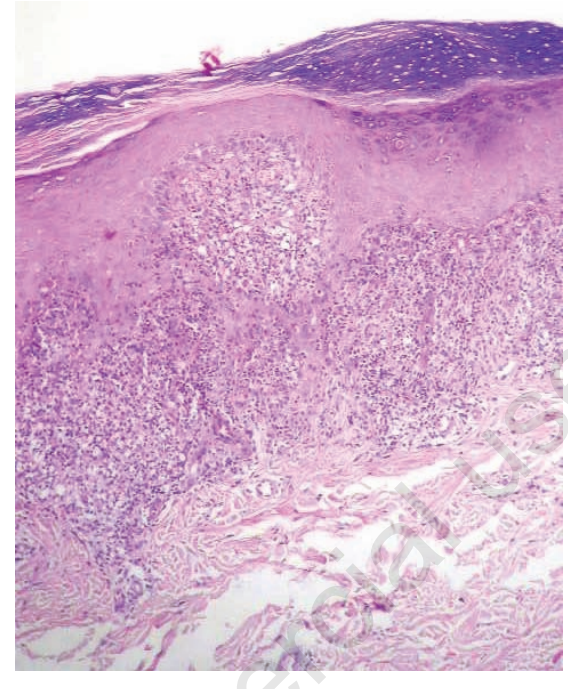

Figure 4. Histopathology showing dense lichenoid infiltrate and saw toothed rete ridges.

planus associated with hepatitis C. Lancet 1995;346:1234.

3. Cribier B, Garnier C, Laustriat D, Heid E. Lichen planus and Hepatitis $\mathrm{C}$ virus infection: an epidemiologic study. J Am Acad Dermatol 1994;31:1070-2.

4. Harper JI ,Trembath RC. Genetics and gen- odermatosis. In: Burns T, Breathnach S, Cox N, Griffith C, editors. Rook's Text book of Dermatology. 7th ed . Oxford: Blackwell Science; 2004. pp. 12-17.

5. McGrath JA, Mclean WHI. Genetics in relation to skin. In: Wolff $K$, Goldsmith LA, Stephen IK, et al., editors. Fitzpatrick's Dermatology in general medicine. 7th ed. New York, NY: McGraw -Hill; 2008. p. 83.

6. Bolognia JL, Orlow SJ, Glick SA. Lines of Blaschko. J Am Acad Dermatol 1994; 31:157- 90.

7. Mobini N, Toussaint S, Kamino $\mathrm{H}$. Noninfectious erythematous, papular and squamous diseases. In: Elder DE, editor . Lever's histopathology of the skin. 10th ed. Philadelphia, PA: Lippincott Williams and Wilkins; 2010. pp.185-186.

8. Saxena AK, Nigam PK. Unilateral Lichen planus. Cutis 1988;42:142-3.

9. Gupta AK, Gorsulowsky DC. Unilateral lichen planus: An unusual presentation. Arch Dermatol 1987;123:295-6.

10. Hartl C, Steen KH, Wegner H, et al. Unilateral linear lichen planus with mucous membrane involvement. Acta DermVenerol 1999;79:145-6.

11. Seo JK, Lee HJ, Lee D, et al. A case of linear lichen planus pigmentosus. Ann Dermatol 2010;22:323-5.

12. Lakshmi C, Divakaran J, Sivaraman A, et al. Painful linear atrophic lichen planus along lines of Blaschko. Ind J Dermatol 2006;51:42-3.

13. Long CC, Finlay AY. Multiple linear lichen planus in the lines of Blaschko. Br $\mathrm{J}$ Dermatol 1996;135:275-6.

14. Braun RP, Barua D, Masouye I. Zosteriform lichen plaus after herpes zoster. Dermatology 1998;197:87-8.

15. Krasowska D, Pietrzak A, Lecewicz-Torun B. Unilateral multiple linear lichen planus following the Blaschko lines recurring after deliveries. Dermatology 2001;202: 340 . 